\title{
Effect of grafting and growing media on the chosen fruit quality compounds and sensory parameters of sweet pepper (Capsicum annuum L.)
}

\author{
Z. Birkás ${ }^{1 *}$ (1), G. Balázs ${ }^{1}$ and Z. Kókai ${ }^{2}$
}

${ }^{1}$ Department of Vegetable and Mushroom Growing, Faculty of Horticultural Science, Szent István University, Ménesi út 44, H-1118 Budapest, Hungary

${ }^{2}$ Department of Postharvest Science and Sensory Evaluation, Faculty of Food Science, Szent István University, Villányi út 35-43, H-1118 Budapest, Hungary

\section{ORIGINAL RESEARCH PAPER}

Received: January 27, 2020 • Accepted: September 08, 2020

Published online: February 12, 2021

(c) 2020 The Author(s)

\section{ABSTRACT}

Grafting is an effective tool in intensive vegetable growing systems that provides standard quality and yield. In the present study, the effect of two rootstocks ('Capsifort F1' and 'Snooker F1') on two commercial varieties ('SV9702 F1' and 'Karpex F1') grown on two media (soil and coconut fibre) was evaluated. During our 2-year study, those instrumental attributes, which have a dominant effect on the chosen chemical components of fruit quality (total soluble solids and titratable acidity) were investigated. Sensory tests were also implemented in order to identify any changes due to the applied technological combinations. Sensory profile analysis was used to identify the descriptive attributes and their perceived intensities. Panellists worked in individual booths with standard lighting, test results were recorded with the Profisens software. In general, it can be concluded that the major instrumental and sensory parameters did not deteriorate as a result of grafting and the application of coconut fibre medium. Some attributes were identified, where the grafted plants on coconut fibre medium showed higher values, namely flesh thickness and shape. Based on our results, grafting and the application of coconut medium is a feasible technological development for growers and agri-business companies.

\section{KEYWORDS}

rootstock-scion, soilless cultivation, total soluble solids, titratable acidity, sensory evaluation

${ }^{*}$ Corresponding author. E-mail: birkas.zita@kertk.szie.hu 


\section{INTRODUCTION}

Sweet pepper (Capsicum annuum L.) has high economic importance worldwide. The area of forced fresh pepper farming in Hungary was constant in the last few years, around 1,550 ha. Beside soil cultivation, the proportion of soilless systems has increased significantly, thus, in 2018, this technology accounted for half of the total volume produced (Fruitveb, 2018).

Pepper can be consumed in many forms (fresh, canned, dried, etc.), and fruits show a high diversity in flavour and texture (Orbán et al., 2011; Ilic et al., 2014).

Vegetable grafting is a tool mainly used in forced cultivation to enhance production and crop quality, and has many advantages and disadvantages, as well (Lee, 2003; Davis et al., 2008). The use of grafted seedlings in pepper production is not well-known compared to other vegetable crops (Lee et al., 2010), however, the use of the appropriate rootstock type can influence yield and decrease environmental stress such as low temperature (Lopez-Marin et al., 2013). Suzuki and Morishita (2002) mention that the scion-rootstock compatibility frequently influences yield and fruit quality. Furthermore, Tsaballa et al. (2013) concluded from their experiments that rootstocks have an influence on the fruit shape; and Fekete et al. (2018) in their studies found that growing technology could influence fruit quality.

Nowadays, in horticulture, quality is becoming a leading attribute over quantity (Schnitzler and Gruda, 2003). From the consumers' point of view, the size of the fruit is one of the most frequently appreciated parameters, which can be correlated with yield (Yetisir et al., 2003). Savvas et al. (2011) mentioned that the higher yield is often achieved by an increase in the number of fruits, which may result in smaller individual fruit weights. In contrast, Donas-Uclés et al. (2014) measured significantly higher pericarp thickness in grafted 'Italian sweet' pepper fruits than in non-grafted ones.

Sweetness and acidity are among the most relevant parameters (in some papers these factors are called 'organoleptic compounds'), which define the sensory properties of bell peppers. Both sugar and acid contents and their ratio are influencing the perceived flavour quality of vegetables and fruits (Kader, 2008). Not only grafting, but also the type of applied rootstock can affect the composition of flavour and aroma compounds (Davis et al., 2008).

The aim of the study was to evaluate the effect of the rootstock and substrate on the sensory parameters and the chosen quality attributes of sweet pepper fruit. In the research, both nongrafted and grafted plants on two commercially available rootstocks, cultivated in two growing media were used.

\section{MATERIALS AND METHODS}

\subsection{Cultivation technology and sampling}

The experiment was carried out in an unheated plastic house at the Research Institute of Szent István University (SZIU) in Soroksár in 2016 and 2017. Two different types of fresh pepper cultivars, 'SV9702 PP F1' (Bayer, white conical type) Bayer and 'Karpex F1' (Bayer, kapia type), were examined as self-rooted and grafted on two different commercial rootstocks 'Snooker F1' (Syngenta) and 'Capsifort F1' (Bayer). For grafting, tube method was chosen, both rootstocks and scions were cut in $45^{\circ}$ angle above the cotyledons and inserted together with the help of a plastic tube. The obtained grafting combinations were 'Snooker'/'SV9702' (S/SV), 'Capsifort'/ 
'SV9702' (C/SV), 'Snooker'/'Karpex' (S/K), and 'Capsifort'/'Karpex' (C/K). The plants were tested in soil (S) and soilless culture (C) with intensive technology using soil mulching, drip irrigation, and training system. For soil cultivation the soil of the plastic house ground was used, which was sandy, the results of soil analysis are presented in Appendix. For soilless cultivation coconut fibre slabs were chosen with a composition of $50 \%$ chips and $50 \%$ fine fibre, the fertilisation was calculated based on water analyses, and the four treatments corresponded to the fertilisation program used in the practice. Each year, white conical samples were transplanted with the density of 4.33 plants $/ \mathrm{m}^{2}$ and picked at commercial maturity, while kapia samples were transplanted with the density of 5.71 plants $/ \mathrm{m}^{2}$ and picked at biological maturity.

\subsection{Analyses of chemical compounds}

The laboratory analyses were carried out at the Analytical Laboratory of Vegetable and Mushroom Growing Department at Szent István University. From each treatment, 6 fruits were blended, and the juice was used for the evaluation of total soluble solids content and titratable acidity.

Total soluble solids (TSS) are associated with the refractive index. The refractive index of samples was measured by a digital refractometer (PAL-1, Atago). Results were expressed as degrees Brix ( ${ }^{\circ}$ Brix).

The titratable acidity (TA) of fruit juice samples was evaluated according to EN 12147: 1996 (EN, 1996) using $0.1 \mathrm{~N} \mathrm{NaOH}$ and phenolphthalein indicator.

\subsection{Sensory analysis}

Sensory tests were carried out in the Sensory Laboratory of SZIU, in booths designed according to ISO 8589 (ISO, 2007), with standard lighting and air circulation. Test sessions and questionnaires were designed and performed with the Profisens software. Samples were coded with 3-digit random numbers, and were presented in a balanced, randomised order. Neutral type of mineral water was used as palate cleanser between samples. The panellists were regular participants of the sensory laboratory's training programs, so they had practical skill in the method of profile analysis. The number of panellists was in accordance with ISO 13299:2016 (ISO, 2016) (between 8 and 16). Attributes were evaluated on unstructured line scales, with labels at both ends. At each session, one of the samples was chosen as an internal reference ('SV9702' S, 'Karpex' S), the research team defined their sensory values prior to the test session. This approach helps to reduce the variation in sensory data. The analysed attributes are summarised in Table 1. Panellists had the opportunity to type in further comments in a textbox at the end of the test sheet.

\subsection{Data analysis}

The data of organoleptic compounds' measurements was analysed with three-way ANOVA by IBM SPSS Toolpack (ver. 22). To separate homogeneous groups, the Tukey's post-hoc test was used.

Sensory data was analysed with one-way ANOVA with the calculation of least significant differences. This step of data analysis is integrated in the Profisens software, which is running as a macro in Microsoft Excel. Principal Component Analysis and Hierarchical Cluster analysis were implemented by PAST, a free statistical software package (version 3.26). 
Table 1. Studied attributes of fresh peppers $(2016,2017)$

\begin{tabular}{lccc}
\hline Attribute & Abbreviation & Low end (value: 0) & High end (value: 100) \\
\hline Shape & S & Narrow & Wide \\
Colour intensity & CI & Pale red & Red \\
Shininess & SH & Dull & Shiny \\
Flesh colour & FC & Heterogeneous & Homogeneous \\
Flesh thickness & FT & Narrow & Wide \\
Size of placenta & SP & Small & Large \\
Crispness & C & Less crisp & Crisp \\
Skin chewability & SC & Hard to chew & Easy to chew \\
Juiciness & J & Dry & Juicy \\
Odour intensity & OI & Not felt & Intensive \\
Sweetness & SW & Not felt & Intensive \\
\hline
\end{tabular}

\section{RESULTS AND DISCUSSION}

\subsection{Analyses of chemical compounds}

Results of the statistical analysis show that there were no significant differences in total soluble solid (TSS) content and titratable acid content (TA) in white type pepper combinations in either one of the two measured years (Table 2) and in kapia type in 2017 either in soil or soilless cultivation.

Kapia combinations cultivated in soil showed significant differences in TSS content in 2016. Grafting 'Karpex' on 'Capsifort' resulted in the highest refractive index, while grafting on 'Snooker' resulted in the lowest. In the same year, for soilless cultivation, the titratable acidity (TA) content showed significant differences between the combinations. The non-grafted 'Karpex' had the highest acid content, in contrast 'Karpex' grafted on 'Snooker' gave the lowest. Colla et al. (2008) also found the same results during their studies. However, our findings are inconsistent with the results of Pogonyi et al. (2005), who found lower TSS content in grafted than non-grafted tomatoes. Additionally, the same parameters in kapia combinations (2016) were similar to the results of Lopez-Marin et al. (2013) measured under unshaded greenhouse conditions.

\subsection{Sensory analysis}

After a general overview on the 4 treatments performed in this study, it can be concluded that in the majority of the attributes there was no significant difference among the samples. This outcome might encourage growers to implement the technology of grafting and soilless cultivation, since there are no major changes in the quality of the sweet pepper fruit. Not always the same attributes showed significant differences from one year to the next. One has to consider that in case of longer-term studies, the changes in the climate might play important role. However, the different set of panellists in the 1st and 2nd years may have an effect also (Table 3).

In 2016, there were differences in the morphological attributes: shape, flesh thickness and placenta size among white conical fruit samples. The widest fruits were found for 'SV9702' C and C/SV C, while the narrowest for 'SV9702' S and C/SV S. Regarding flesh thickness, 'SV9702' 
Table 2. Total soluble solids (TSS) and titratable acidity (TA) contents of pepper fruits depending on the growing media $(2016,2017)$

\begin{tabular}{|c|c|c|c|c|c|c|c|c|}
\hline \multicolumn{9}{|c|}{ White type } \\
\hline & \multicolumn{4}{|c|}{2016} & \multicolumn{4}{|c|}{2017} \\
\hline & \multicolumn{2}{|c|}{ Soil culture } & \multicolumn{2}{|c|}{ Coconut fibre } & \multicolumn{2}{|c|}{ Soil culture } & \multicolumn{2}{|c|}{ Coconut fibre } \\
\hline & TSS $\left(\right.$ Brix $\left.^{\circ}\right)$ & TA (\%) & TSS $\left(\right.$ Brix $\left.^{\circ}\right)$ & TA (\%) & TSS $\left(\right.$ Brix $\left.^{\circ}\right)$ & TA (\%) & TSS $\left(\right.$ Brix $\left.^{\circ}\right)$ & TA (\%) \\
\hline SV 9702 & $4.01 \pm 0.208^{\mathrm{a}}$ & $0.10 \pm 0.014^{\mathrm{a}}$ & $4.16 \pm 0.148^{\mathrm{a}}$ & $0.09 \pm 0.006^{\mathrm{a}}$ & $4.22 \pm 0.058^{\mathrm{a}}$ & $0.08 \pm 0.003^{\mathrm{a}}$ & $4.29 \pm 0.107^{\mathrm{a}}$ & $0.07 \pm 0.004^{\mathrm{a}}$ \\
\hline S/SV & $4.19 \pm 0.173^{\mathrm{a}}$ & $0.10 \pm 0.009^{\mathrm{a}}$ & $4.01 \pm 0.103^{\mathrm{a}}$ & $0.10 \pm 0.012^{\mathrm{a}}$ & $4.19 \pm 0.074^{\mathrm{a}}$ & $0.08 \pm 0.004^{\mathrm{a}}$ & $4.13 \pm 0.126^{\mathrm{a}}$ & $0.07 \pm 0.003^{\mathrm{a}}$ \\
\hline $\mathrm{C} / \mathrm{SV}$ & $3.99 \pm 0.069^{\mathrm{a}}$ & $0.09 \pm 0.007^{\mathrm{a}}$ & $4.18 \pm 0.160^{\mathrm{a}}$ & $0.10 \pm 0.010^{\mathrm{a}}$ & $4.08 \pm 0.142^{\mathrm{a}}$ & $0.07 \pm 0.005^{\mathrm{a}}$ & $4.11 \pm 0.096^{\mathrm{a}}$ & $0.07 \pm 0.003^{\mathrm{a}}$ \\
\hline \multicolumn{9}{|l|}{ Kapia type } \\
\hline & \multicolumn{4}{|c|}{2016} & \multicolumn{4}{|c|}{2017} \\
\hline & \multicolumn{2}{|c|}{ Soil culture } & \multicolumn{2}{|c|}{ Coconut fibre } & \multicolumn{2}{|c|}{ Soil culture } & \multicolumn{2}{|c|}{ Coconut fibre } \\
\hline & TSS (Brixº) & TA (\%) & TSS $\left(\right.$ Brix $\left.^{\circ}\right)$ & TA (\%) & TSS $\left(\right.$ Brix $\left.^{\circ}\right)$ & TA $(\%)$ & TSS $\left(\right.$ Brix $\left.^{\circ}\right)$ & TA $(\%)$ \\
\hline Karpex & $6.93 \pm 0.480^{\mathrm{ab}}$ & $0.12 \pm 0.003^{\mathrm{a}}$ & $6.56 \pm 0.191^{\mathrm{a}}$ & $0.13 \pm 0.019^{b}$ & $7.91 \pm 0.597^{\mathrm{a}}$ & $0.15 \pm 0.027^{\mathrm{a}}$ & $7.88 \pm 0.250^{\mathrm{a}}$ & $0.15 \pm 0.015^{\mathrm{a}}$ \\
\hline$S / K$ & $6.42 \pm 0.366^{\mathrm{a}}$ & $0.11 \pm 0.022^{\mathrm{a}}$ & $6.12 \pm 0.137^{\mathrm{a}}$ & $0.10 \pm 0.009^{\mathrm{a}}$ & $8.23 \pm 0.339^{\mathrm{a}}$ & $0.16 \pm 0.018^{a}$ & $7.54 \pm 0.486^{\mathrm{a}}$ & $0.14 \pm 0.008^{\mathrm{a}}$ \\
\hline $\mathrm{C} / \mathrm{K}$ & $7.38 \pm 0.302^{\mathrm{b}}$ & $0.13 \pm 0.009^{\mathrm{a}}$ & $6.50 \pm 0.321^{\mathrm{a}}$ & $0.12 \pm 0.006^{\mathrm{ab}}$ & $8.12 \pm 0.126^{\mathrm{a}}$ & $0.16 \pm 0.009^{\mathrm{a}}$ & $7.41 \pm 0.407^{\mathrm{a}}$ & $0.12 \pm 0.019^{\mathrm{a}}$ \\
\hline \multicolumn{9}{|c|}{$\begin{array}{l}\text { S/SV: 'Snooker'/'SV9702'; C/SV: 'Capsifort'/'SV9702'; S/K:'Snooker'/'Karpex'; C/K: 'Capsifort'/'Karpex'. } \\
\text { Letters 'a' and 'b' mean homogeneous groups in the same columns by Tukey's test, } P<0.05 \text {. }\end{array}$} \\
\hline
\end{tabular}


Table 3. Significant differences in the sensory data for different treatments. Only those attributes are shown, where a significant difference exists (Values in brackets are standard deviation values)

\begin{tabular}{|c|c|c|c|c|c|c|c|}
\hline \multirow{2}{*}{$\begin{array}{l}\text { Sensory attributes } \\
2016\end{array}$} & \multirow{2}{*}{$P$ value } & \multicolumn{6}{|c|}{ Treatments (white conical type) } \\
\hline & & SV9702 S & SV9702 C & S/SV S & S/SV C & C/SV S & C/SV C \\
\hline Shape & $3.17553 \mathrm{E}-08$ & 60.0 & $77.4(5.54)$ & $73.4(9.11)$ & $73(4.59)$ & $62.7(6.84)$ & $77.4(9.00)$ \\
\hline Flesh thickness & 0.003 & 45.0 & $59.1(9.19)$ & $57.5(10.15)$ & $57.3(11.13)$ & $51.5(9.86)$ & $60.3(9.31)$ \\
\hline Placenta size & 0.011 & 40.0 & $54.5(14.86)$ & $52.1(11.94)$ & $54.6(19.79)$ & $44.6(11.09)$ & $60.1(9.78)$ \\
\hline \multirow{3}{*}{$\begin{array}{l}2017 \\
\text { Placenta size }\end{array}$} & & & & & & & \\
\hline & 0.015 & 40.0 & $46.8(7.96)$ & $42.3(12.71)$ & $38.3(9.82)$ & $31.4(9.54)$ & $32.4(16.08)$ \\
\hline & & \multicolumn{6}{|c|}{ Treatments (kapia type) } \\
\hline 2016 & & Karpex S & Karpex C & $\mathrm{S} / \mathrm{K} \mathrm{S}$ & $\mathrm{S} / \mathrm{K} \mathrm{C}$ & $\mathrm{C} / \mathrm{K} \mathrm{S}$ & $\mathrm{C} / \mathrm{K} \mathrm{C}$ \\
\hline Shape & $1.65195 \mathrm{E}-07$ & 40.0 & $61.3(11.99)$ & $40.4(12.52)$ & $52.4(12.99)$ & $32.8(9.40)$ & $45.2(7.86)$ \\
\hline Odour intensity & 0.044 & 70.0 & $67.5(7.01)$ & $65.4(9.97)$ & $60.7(11.20)$ & $69.5(5.41)$ & $61.2(11.67)$ \\
\hline \multicolumn{8}{|l|}{2017} \\
\hline Flesh thickness & 0.047 & 75.0 & $67.1(13.20)$ & 70.4 (13.18) & $63.0(10.09)$ & $61.9(14.45)$ & $73.5(8.10)$ \\
\hline
\end{tabular}

S/SV: 'Snooker'/'SV9702'; C/SV: 'Capsifort'/'SV9702'; S/K:'Snooker'/'Karpex'; C/K: 'Capsifort'/'Karpex'.

S: soil; C: soilless culture. 
S was the thinnest, while C/SV C and 'SV9702' C were the thickest. In this attribute, the differences were much smaller compared to the ones obtained for the 'shape' attribute. The smallest placenta was found in 'SV9702' S and in C/SV S, the largest in C/SV C and in S/SV C. In the 2017 experiment, only the size of placenta showed significant differences. The two grafted combinations grown in soil were different in this attribute. In case of coconut fibre medium, selfrooted peppers had larger placenta than the ones grafted on 'Capsifort' rootstock.

In case of the kapia type, the following results were obtained. In the 2016 research year, only the shape and the odour intensity were different (Table 3). The self-rooted, coconut medium grown combination had significantly wider fruits. The grafted ('Snooker') combination, grown on coconut fibre, also differed significantly from all others except $\mathrm{C} / \mathrm{K} \mathrm{C}$. The other significantly different attribute was odour intensity, where the grafted ('Snooker' rootstock) grown in coconut medium had the lowest odour intensity value. The self-rooted, soil grown and the 'Capsifort' grafted, soil-grown combinations had the most intense odour. In 2017, flesh thickness was significantly different among the attributes. In the literature, Donas-Uclés et al. (2014) reported generally thicker flesh for the grafted combinations. In our study, the $\mathrm{C} / \mathrm{K} \mathrm{C}$ and 'Karpex' $\mathrm{S}$ showed higher values in this attribute, while $\mathrm{C} / \mathrm{K} \mathrm{S}$ and $\mathrm{S} / \mathrm{K} \mathrm{C}$ were the thinnest.

In Fig. 1, the 2016 white conical type's sensory and morphological features are shown. The PCA biplot is showing the relative position of the samples and their measured parameters. According to the distribution of the samples, the grafted and self-rooted combinations are clearly separated. Combinations grown in coconut fibre separated from the soil grown ones. In the one-way ANOVA, shape, flesh thickness, and the size of the placenta were significant. On the PCA plot, these 3 attributes point towards 'SV9702' C and C/SV C, which means that these attributes were characteristic to these two combinations. Titratable acidity and sweetness point to opposite directions, which shows that the panel was able to distinguish the sweet character of the samples. Shininess and skin chewability were also pointing to the same quadrant of the biplot. The Brix $^{\circ}$ value vector is close to the flesh thickness and crispiness and was plotted on the right side of PC 2 axis like sweetness and juiciness.

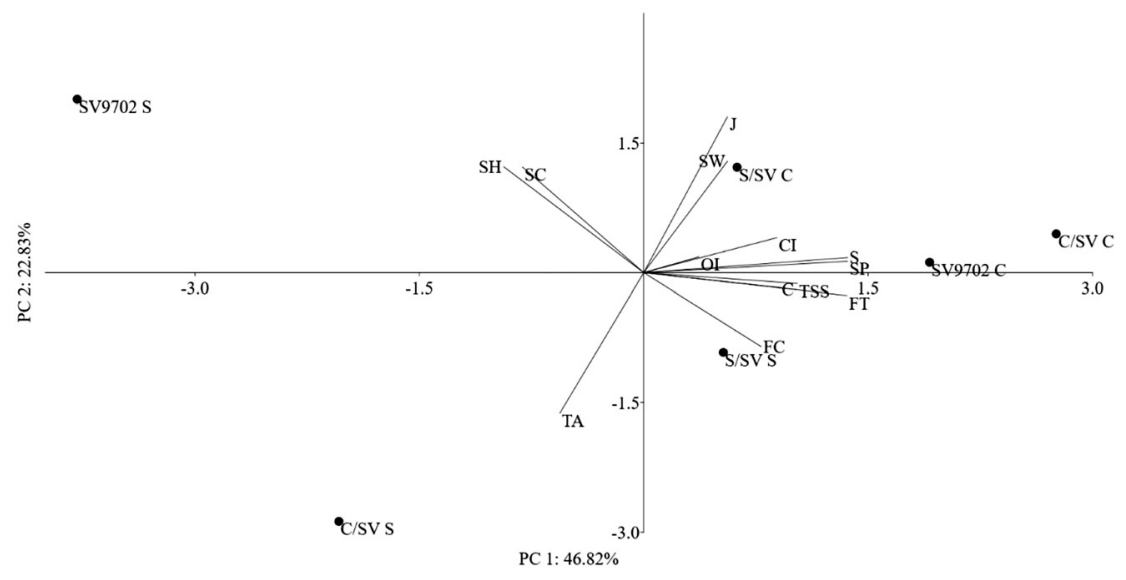

Fig. 1. PCA biplot of the 2016, white conical type bell pepper samples' sensory and morphological parameters 


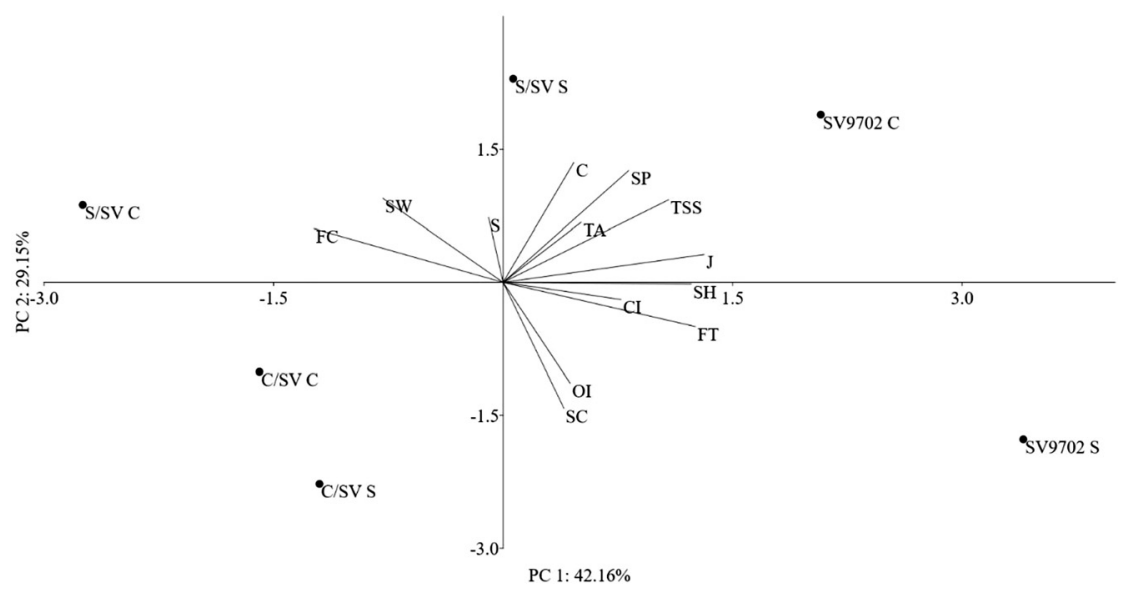

Fig. 2. PCA biplot of the 2017, white conical type bell pepper samples' sensory and morphological parameters

Fig. 2 shows also a clear distinction between the grafted and self-rooted combinations. The grafted objects are on the left-hand side of PC1 (except S/SV S, which is very close to the axis). The vectors of 'sweetness' and 'flesh colour' are pointing towards the left part of the plot, referring to that these attributes were more characteristic for these items.

During data analysis, hierarchical cluster analysis (HCA) was also performed, the resulting dendrogram is shown in Fig. 3. On the left hand of the plot, the two self-rooted combinations are forming one cluster.

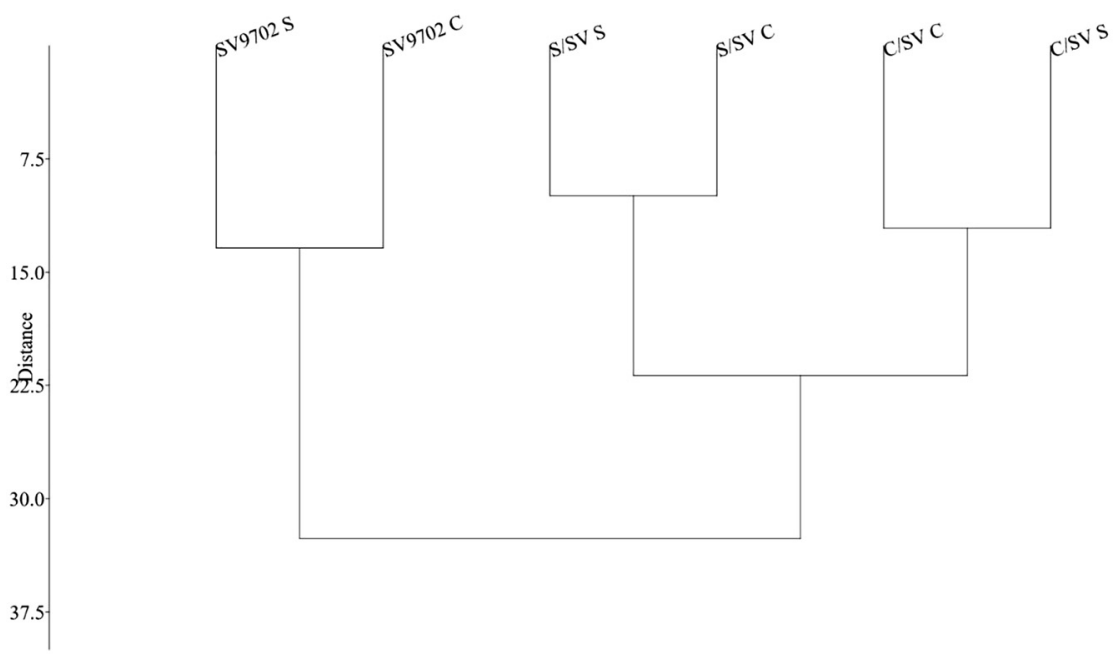

Fig. 3. Hierarchical cluster analysis of the white conical type bell pepper's data (research year 2017) 
In Fig. 4, the self-rooted combinations are positioned in the lower right part of the plot, while the grafted ones are located more on the upper part, these two groups are mostly separated. Concerning the sensory attributes, the sweetness intensity and the TSS value point to the same direction, while 'Karpex' S (which had the smallest placenta) is positioned on the opposite side of the placenta size vector.

In 2017, kapia samples of the two different growing media separated from each other (Fig. 5). The vector of the significantly different attribute (flesh thickness) points to that half of the diagram, where the two samples with the highest values are found ('Karpex' $S$ and $\mathrm{C} / \mathrm{K} \mathrm{C}$ ).

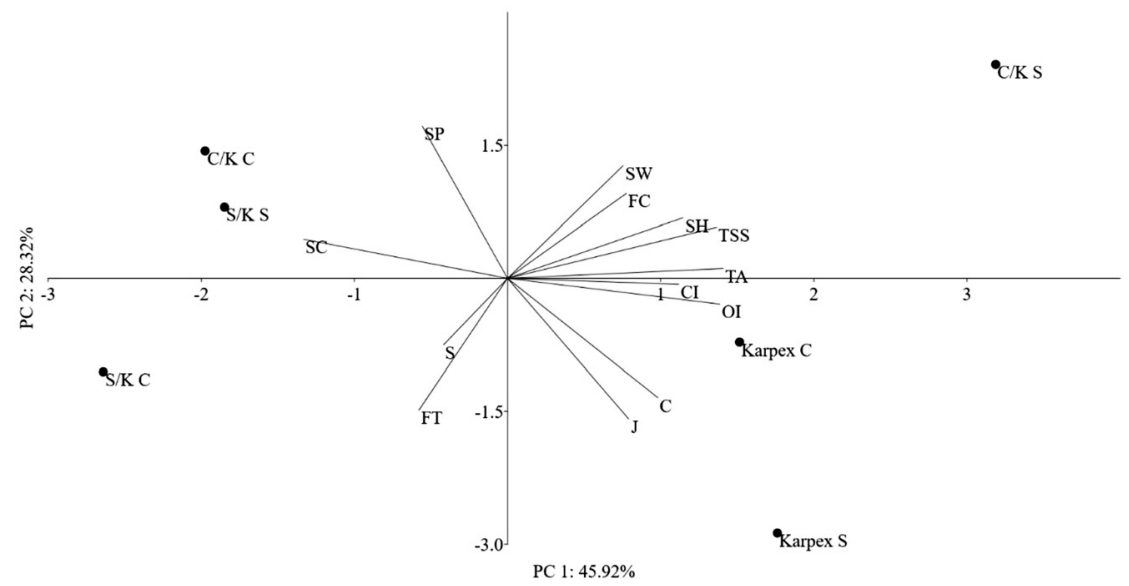

Fig. 4. PCA biplot of the 2016, kapia type samples' sensory and morphological parameters

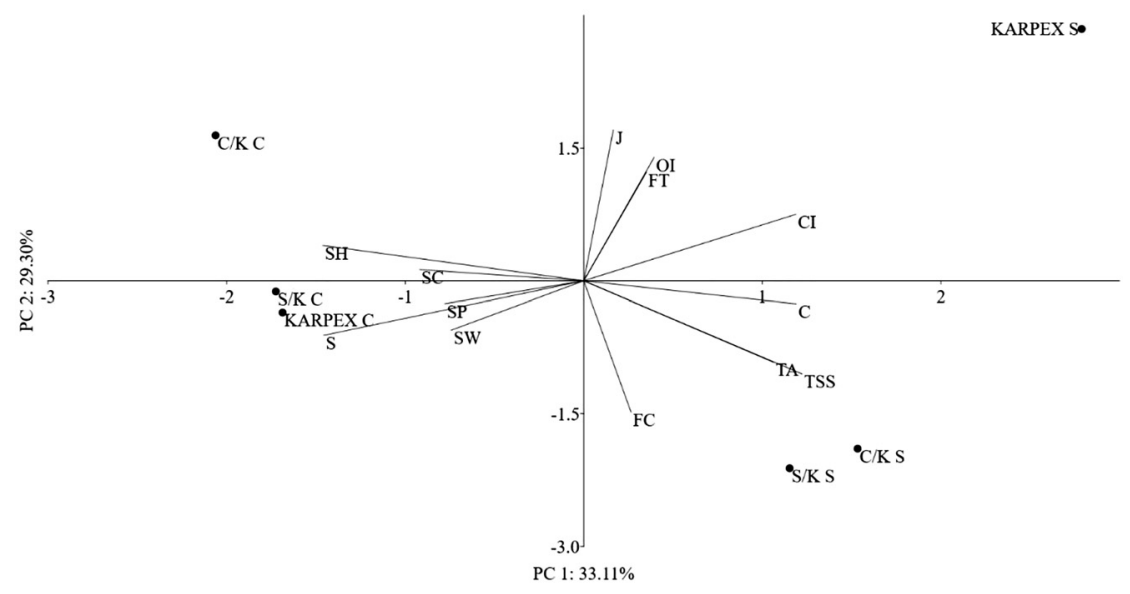

Fig. 5. PCA biplot of the 2017, kapia type samples' sensory and morphological parameters 


\section{CONCLUSIONS}

Based on the laboratory analyses, it can be concluded that neither grafting nor growing medium have significant effect on water soluble solid and total acid contents in the tested white type pepper combinations in 2016 and 2017 and the kapia type combinations in 2017.

Based on the sensory tests, it is clear that in most of the parameters there were no significant differences among the treatments. The fruits had different flesh thicknesses in both pepper types: for the white conical type year 2016 was significant, for the kapia type year 2017 brought larger differences. In case of the white conical type, the 'Capsifort' grafted plants in coconut medium showed higher values in flesh thickness. These results show that the 'Capsifort'-grafted combination grown in coconut medium resulted in the highest flesh thickness values. Another morphological attribute was shape, where the C/SV C ('Capsifort'-grafted 'SV9702', coconut medium) resulted in wider fruits (research year 2016). In the kapia study, the grafted plants had wider fruits in coconut medium (2016).

Our research shows that the general quality parameters of the fruits (both physical and sensory) do not show negative changes either due to the application of grafting or to the use of coconut fibre medium. Those parameters that are used as quality indicators in trade and consumer perception (shape, flesh thickness) showed beneficial changes, especially in the case of 'Capsifort' rootstock and coconut fibre medium combination. Based on our study, we encourage growers and agro-business companies to implement this grafting and coconut fibre medium combination to a greater extent. This would contribute to more standard fruit quality.

\section{ACKNOWLEDGEMENT}

The research was carried out in the frame of EFOP-3.6.1-16-2016-00016 Specialisation of the research and education profiles of the SZIE Campus of Szarvas with intelligent specialisation: agricultural water management, hydroponic crop production, alternative field crop production, and precision mechanical engineering connected to these fields. The research was supported by the Ministry for Innovation and Technology within the framework of the Higher Education Institutional Excellence Program (NKFIH-1159-6/2019) in the scope of plant breeding and plant protection researches of Szent István University. The project was supported by the European Union and co-financed by the European Social Fund grant agreement no. EFOP-3.6.3-VEKOP16-2017-00005.

\section{REFERENCES}

Colla, G., Rouphael, Y., Cardarelli, M., Temperini, O., Rea, E., Salerno, A., and Pierandrei, F. (2008). Influence of grafting on yield and fruit quality of pepper (Capsicum annuum L.) grown under greenhouse conditions. In: IV International Symposium on Seed, Transplant and Stand Establishment of Horticultural Crops; Translating Seed and Seedling, Acta Hort., 782: 359-364. 
Davis, A.R., Perkins-Veazine, P., Hassel, R., Levi, A., King, S.R., and Zhang, X. (2008). Grafting effects on vegetable quality. HortScience, 43(6): 1670-1672.

Donas-Uclés, F., Jiménez-Luna, M.M., Gongora-Corral, J.A., Pérez-Madrid, D., Verde-Fernandez, D., and Camacho-Ferre, F. (2014). Influence of three rootstocks on yield and commercial quality of 'Italian sweet' pepper. Ciência e Agrotecnologia, 38(6): 538-545.

EN (1996). Fruit and vegetable juices - determination of titratable acidity. EN 12147: 1996.

Fekete, D., Balázs, G., Bőhm, V., Várvölgyi, E., and Kappel, N. (2018). Sensory evaluation and electronic tongue for sensing grafted and non-grafted watermelon taste attributes. Acta Alimentaria, 47: 487-494.

Fruitveb (2018). Annual report of Hungarian fruit and vegetable sector. Published by FRTUITVEB, 4.

Ilic, Z.S., Mirecki, N., and Fallik, E. (2014). Cultivars differences in keeping quality and bioactive constituents of bell pepper fruit during prolonged storage. JBT, 4(1): 313-318.

ISO (2007). Sensory analysis-general guidance for the design of test rooms. ISO 8589:2007.

ISO (2016). Sensory analysis-methodology—general guidance for establishing a sensory profile. ISO 13299:2016.

Kader, A.A. (2008). Flavor quality of fruits and vegetables. Journal of the Science of Food and Agriculture, 88: $1863-1868$.

Lee, J.M. (2003). Advances in vegetable grafting. Chronica Horticulturae, 43: 13-19.

Lee, J.M., Kubota, C., Tsao, S.J., Bie, Z., Hoyos-Echevarria, P., Morra, L., and Oda, M. (2010). Current status of vegetable grafting: diffusion, grafting techniques, automation. Scientia Horticulturae - Amsterdam, 127(2): 93-105.

Lopez-Marin, J., Gonzalez, A., Perez-Alfocea, F., Egea-Gilbert, C., and Fernandez, J.A. (2013). Grafting is an efficient alternative to shading screens to alleviate thermal stress in greenhouse grown sweet pepper. Scientia Horticulturae - Amsterdam, 149: 39-46.

Orbán, C., Füstös, Z., and Gilinger, M.P. (2011). Changes in the quality of sweet pepper types during the post-harvest ripening. Journal on Processing and Energy in Agriculture, 15(2): 109-112.

Pogonyi, A., Pék, Z., Helyes, L., and Lugasi, A. (2005). Effect of grafting on the tomato's yield, quality and main fruit components in spring forcing. Acta Alimentaria, 34: 453-462.

Savvas, D., Savva, A., Ntatsi, G., Ropokis, A., Karapanos, I., Krumbein, A., and Olympios, A. (2011). Effect of three commercial rootstocks on mineral nutrition, fruit yield, and quality of salinized tomato. Journal of Soil Science and Plant Nutrition, 174: 154-162.

Schnitzler, W.H. and Gruda, N. (2003). Quality issues of greenhouse production. Acta Horticulturae, 614: 663-674.

Suzuki, T. and Morishita, M. (2002). Effects of scion and rootstock cultivars on growth and yield of eggplant cultured under two fertilizer levels. Journal of the Japanese Society for Horticultural Science, 71(4): 568-574.

Tsaballa, A., Athanasiadis, C., Pasentsis, K., Ganopoulos, I., Nianiou-Obeidat, I., and Tsaftaris, A. (2013). Molecular studies of inheritable grafting induced changes in pepper (Capsicum annuum) fruit shape. Scienta Horticulturae, 149: 2-8.

Yetisir, G., Sari, N., and Yücel, S. (2003). Rootstock resistance to Fusarium wilt and effect on watermelon fruit yield and quality. Phytoparasitica, 31: 163-169. 


\section{APPENDIX}

Table A1: Results of soil analyses

\begin{tabular}{ccccccccccc}
\hline & $\mathrm{pH}(\mathrm{KCl})$ & $\mathrm{KA}$ & $\begin{array}{c}\text { Salinity } \\
\mathrm{m} / \mathrm{m} \%\end{array}$ & $\begin{array}{c}\mathrm{CaCO}_{3} \\
\mathrm{~m} / \mathrm{m} \%\end{array}$ & $\begin{array}{c}\text { Humus } \\
\mathrm{m} / \mathrm{m} \%\end{array}$ & $\begin{array}{c}\mathrm{NO}_{2}+\mathrm{NO}_{3}-\mathrm{N} \\
\mathrm{mg} / \mathrm{kg}\end{array}$ & $\begin{array}{c}\mathrm{P}_{2} \mathrm{O}_{5} \\
\mathrm{mg} / \mathrm{kg}\end{array}$ & $\begin{array}{c}\mathrm{K}_{2} \mathrm{O} \\
\mathrm{mg} / \mathrm{kg}\end{array}$ & $\begin{array}{c}\mathrm{Cu} \\
\mathrm{mg} / \mathrm{kg}\end{array}$ & $\begin{array}{c}\mathrm{Mn} \\
\mathrm{mg} / \mathrm{kg}\end{array}$ \\
\hline 2016 & 7.61 & 24 & 0.03 & 1.43 & 2.42 & 7 & 565 & 125 & 0.5 & 23.5 \\
2017 & 7.22 & 24 & 0.013 & 1.36 & 3.71 & 4.5 & 587 & 173 & 0.5 & 23 \\
\hline
\end{tabular}

Open Access. This is an open-access article distributed under the terms of the Creative Commons Attribution 4.0 International License (https://creativecommons.org/licenses/by/4.0/), which permits unrestricted use, distribution, and reproduction in any medium, provided the original author and source are credited, a link to the CC License is provided, and changes - if any - are indicated. (SID_1) 